\title{
Towards a Strategy to Implement the China Wetland Mapping Using Landsat TM
}

\author{
Haiying Zhang, Zhenguo Niu *, Yaomin Zheng \\ (State Key Laboratory of Remote Sensing Science, Institute of Remote Sensing and Digital \\ Earth, Chinese Academy of Sciences, Beijing 100101, China; zhanghy@radi.ac.cn (H.Z.); \\ zhengym@radi.ac.cn (Y.Z.))
}

*Corresponding author: niuzg@radi.ac.cn

\begin{abstract}
Wetlands are among the most bio-diverse and highest productivity ecosystems on earth, making their monitoring a high priority to conservation, protection and management interests. Although visual interpretation of satellite images is generally precise for monitoring wetlands, recent works have emphasized computerized classification methods because of the reduction in analyst time. However, it is difficult to automatically identify wetland solely based on spectral characteristics due to the complexity of wetland ecosystems. The ability to extract wetland information rapidly and accurately is the basis and the key to wetland mapping at a large scale. Here we propose an operational method to map China wetlands based on Landsat TM data and ancillary data. On the basis of theoretical analysis of wetland automatic classification, we developed a revised multi-layer wetland classification scheme and a rule-based classification model. In the latter, supervised classification (SVM and decision tree) and unsupervised classification (ISODATA) methods were tested. Four Landsat TM images, representing various wetland eco-regions in China (i.e. the Sanjiang Plain in the northeast China, the North China Plain, the Zoige Plateau in the southwest China and the Pearl River Estuary in southeast China), were automatically classified. The overall classification accuracies were $86.57 \%, 96.00 \%, 84.51 \%$ and $88.30 \%$, respectively, which we considered to be satisfactory accuracy. Our results indicate that issues such as the resolution of geographic data and the understanding of wetland samples should be carefully addressed in the future.
\end{abstract}

Keywords: rule-based classification model; wetland remote sensing; SVM; TC-Wetness; China

\section{Introduction}

Wetlands are of increasing importance to humanity for providing ecological goods and services. To effectively protect and wisely use wetlands, society requires a complete understanding of the spatial and temporal distribution of wetlands [1]. Accurately mapping wetlands and monitoring their dynamic changes provide the scientific foundation for wetland protection and restoration, as well as biodiversity protection $[2,3]$. As a timely and cost-effective technique for monitoring wetlands, remote sensing has been extensively adopted in wetland mapping [4-6]. 
Currently, all types of wetlands can be automatically classified by remote sensing $[3,5,7,8]$. However, to separate wetlands from other types of land cover using automatic methods for land cover mapping at a large scale is still a challenge. Nakaegawa [9] compared water-related land cover in six $1-\mathrm{km}$ global land cover datasets and found that the global mean per-pixel consistency of wetlands in these widely referenced global land cover datasets is much lower than that of snow and ice, or open water.

For many study areas, the use of hyperspectral or radar data may be difficult due to data availability, cost constraints, and the requirement for advanced processing. Therefore, optical-based multispectral data such as Landsat Thematic Mapper (TM) images are still the most common and important data sources for wetland classification and monitoring [10-18].

Landsat is arguably most successful earth-observing satellite, having been in operation for more than 40 years and providing massive amounts of satellite data for environmental and ecological research. Owing to both large coverage and fine spatial resolution, the Landsat TM5 is the most appropriate data source for wetland mapping at large scale. Recently, China wetlands have been mapped mainly by manual interpretation, utilizing Landsat MSS, TM and ETM+ [19-22]. Although manual interpretation of wetland has higher accuracy, it is frequently more time and labor consuming. The combination of automatic classification approaches with auxiliary data and expert knowledge is the most promising method for large scale wetlands mapping.

Our study aims to develop an operational approach to mapping wetlands across China, combining supervised classification and unsupervised classification, based on Landsat TM images and ancillary data.

\section{Data and method}

\subsection{Theoretical analysis of automatic wetland classification}

Although there are various definitions of wetlands, water, being the key component of the wetland ecosystem, has been generally accepted as a necessary ingredient across the geography, environmentology and ecology domains. Wetlands were mapped according to the three-parameter approach defined in the USA Army Corps of Engineers Wetland Delineating Manual [23]. The manual defines wetlands as areas that exhibit hydrophytic vegetation, hydric soils, and wetland hydrology or standing water. A key indicator of wetland hydrology is saturation of land surfaces by water, which is the foundation of wetlands discrimination from other land cover by remote sensing. Water absorbs electromagnetic energy at infrared wavelength, resulting in lower reflectance values for saturated areas than for drier upland sites. Based on this principle, TM band 5 was divided into upland and wetland categories by applying gray-level threshold techniques [13]. Landmann et al. [24] used the wet season near infrared (NIR) as a surrogate for flooding, combined with NDVI, to map wetlands in semi-arid Africa.

The tasseled cap (TC) transformation has, since its formulation in 1976 for Landsat Multispectral 
Scanner (MSS) data [25], been applied as both a descriptive and analytical tool in a variety of ecological studies. The feature of greenness, as a proxy for amount of photosynthetically active vegetation, has been mostly employed in monitoring forest [26]. The feature of wetness, as a proxy of soil moisture, can also be used as an effective index of the water content of various land cover types in the image. Since water content is the key feature employed to discriminate wetlands from uplands, we can theoretically use this index to map wetlands.

Ancillary data, such as topographic data, can also be beneficial to wetland classification, since the spatial distribution of wetlands is highly correlated to topography. The analysis of the characteristics of China wetlands shows that about $94 \%$ of wetlands are distributed in areas with slope less than 3 degrees [21]. Other studies found that topography could enhance the classification accuracy of wetland mapping, compared to using only spectral information $[3,11]$. Digital Elevation Models (DEM) are often chosen to simulate the potential wetlands distribution [27-29], though the accuracy of the DEM was one of important limiting factors for wetland simulation studies [30].

\subsection{Wetlands classification scheme oriented to remote sensing automatic classification}

Though there have been various wetland definitions and schemes, which served for a variety of aims and were applied at different spatial scales, there is no universal wetland classification scheme oriented for wetland mapping based on remote sensing. The wetlands classification system adopted by Ramsar [31] was oriented for wetlands management, though less suitable for wetland mapping based on remote sensing. Furthermore, water-related land cover types adopted by existing global land cover datasets are too simple to meet the requirements of wetland mapping and management. The wetland classification scheme adopted in the manual mapping of China wetland [22], is not suitable for wetland automatic classification because some wetland subtypes, such as rivers and lakes, cannot be separated from each other when automatic classification methods are employed. A revised wetland classification scheme, considering characteristics of wetlands ecosystems and application of automatic classification technologies, is put forward in Table 1 . In this scheme, various characteristics of wetlands are classified based on different data sources and approaches. Wetland climatic characteristics can be divided into seven categories based on annual cumulative temperature $(>0)$, including tropical $(>8000)$, subtropical (6200-8000), warm (5300-6200), warm temperate (3700-5300), cool temperate (2300-3700), cold temperate (1300-2300) and frigid $(<1300)$; geochemical characteristics of wetland can be described from eutrophication (hypertrophic, mesotrophic, oligotrophic) and $\mathrm{PH}$. 
Table 1.Wetland classification scheme oriented for automatic computer classification

\begin{tabular}{|c|c|c|c|c|c|c|c|c|c|c|c|c|}
\hline \multirow[t]{2}{*}{$\begin{array}{l}\text { Land cover } \\
\text { type }\end{array}$} & \multirow[t]{2}{*}{ code } & \multirow[t]{2}{*}{$\begin{array}{l}\text { Land over } \\
\text { subtype }\end{array}$} & \multirow[t]{2}{*}{ code } & \multicolumn{2}{|r|}{ Wetness } & \multicolumn{2}{|c|}{$\begin{array}{l}\text { Topographic } \\
\text { characteristic } \\
\text { Slope }\left(>5^{\circ}\right)\end{array}$} & \multicolumn{2}{|c|}{$\begin{array}{c}\text { Hydro } \\
\text { characteristic(inun } \\
\text { dated duration) }\end{array}$} & \multirow{2}{*}{$\begin{array}{c}\text { Climatic } \\
\text { characteristic* } \\
\text { Annual } \\
\text { cumulative } \\
\text { temperature } \\
>0{ }^{\circ} \mathrm{C}\end{array}$} & \multicolumn{2}{|c|}{$\begin{array}{c}\text { Geochemical } \\
\text { characteristic } * *^{*}\end{array}$} \\
\hline & & & & dry & wet & 0 & 1 & 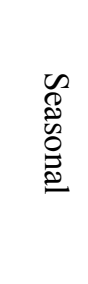 & $\begin{array}{l}\text { D. } \\
\stackrel{0}{0} \\
\text { E. } \\
\text { E. }\end{array}$ & & 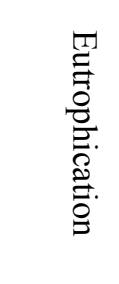 & $\Xi$ \\
\hline Bareland & 10 & & & - & Flooded wetland + & + & - & / & l & / & l & / \\
\hline \multirow[t]{3}{*}{ Vegetation } & 20 & & & & & & & / & l & I & l & I \\
\hline & & Wood & 21 & - & Forest wetland+ & + & - & / & / & / & / & l \\
\hline & & Shrub & 22 & - & Shrub swamp + & + & - & / & l & / & l & I \\
\hline
\end{tabular}




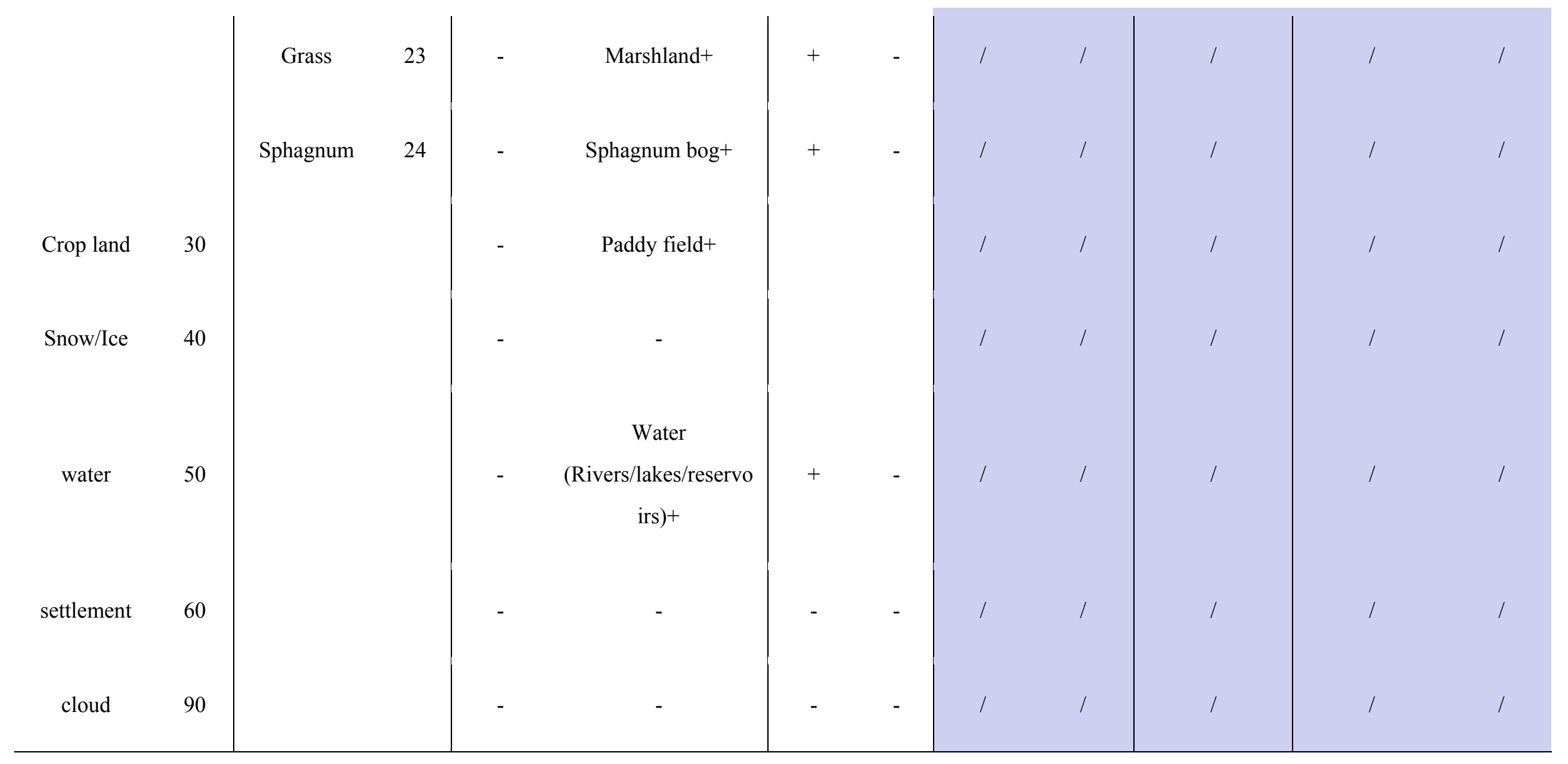

“+”means the accepted wetland category; “-”means the unaccepted land cover category; "“” means the further wetland characteristics not included in this study; 


\subsection{Study areas}

Four representative wetland regions in China were chosen to examine the feasibility of wetland mapping by automatic classification, where various wetland categories, including marshland, freshwater wetland in agricultural area, alpine peatlands and coastal mangroves, are extensive (Fig. 1).

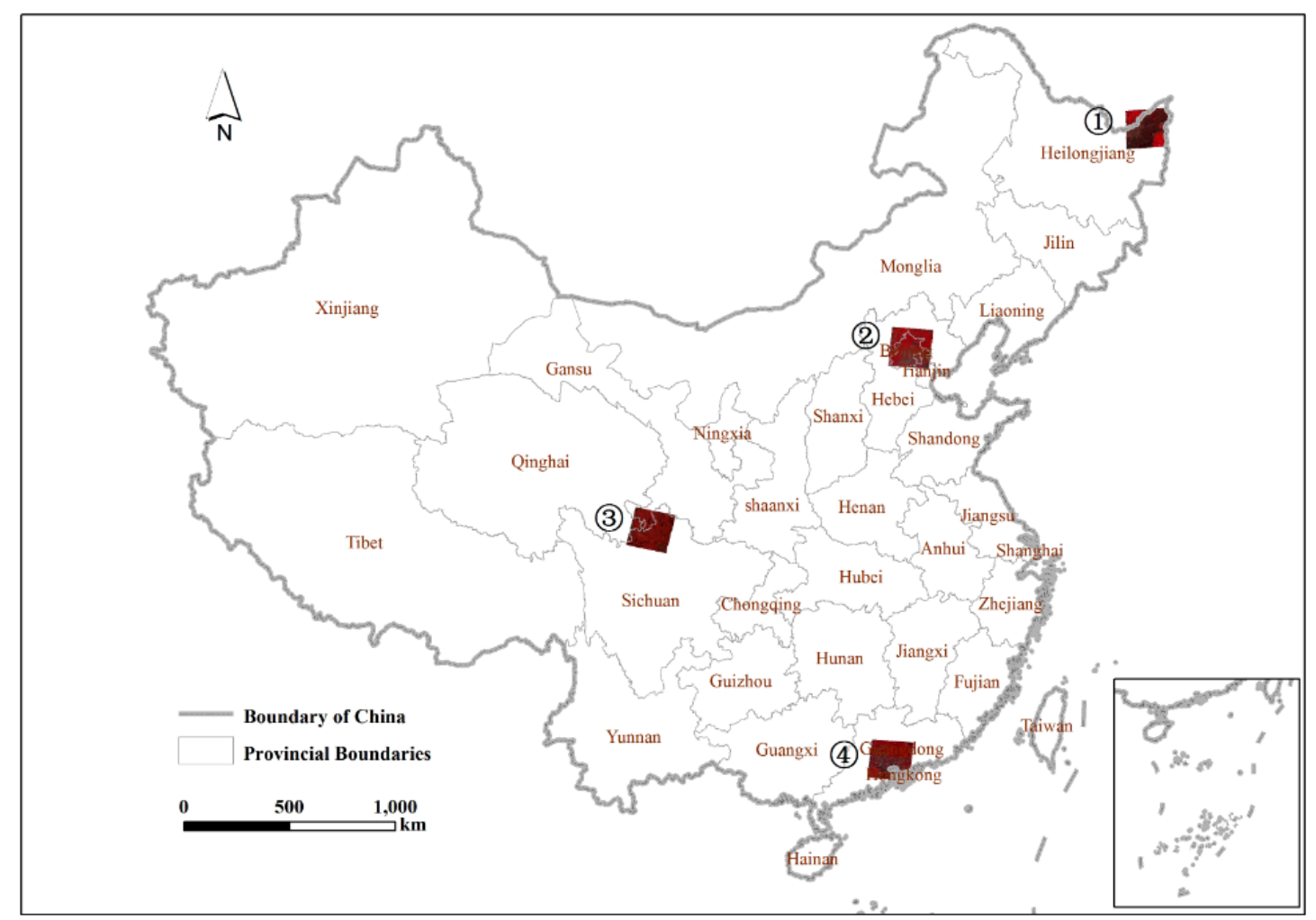

Fig. 1. Location map of sample Landsat TM images

(1) Sanjiang Plain in Northeast China, containing extensive natural marshlands, has an altitude of less than $100 \mathrm{~m}$ and annual precipitation of $580 \mathrm{~mm}$. Perennial inundated marshlands and seasonal inundated meadows are the main wetland categories, where Carex lasiocarpa, Carexmeyeriana and Calamagrostis angustifolia are the main vegetation types. The soil types are meadow bog soil and peat bog soil.

(2) The long history of agricultural exploitation and urbanization in the North China Plain leads to little remnant of wetlands in this region, which caused deterioration of water resource balance. To automatically map those sporadic wetlands is much more challenging in the context of a developed agricultural region due to the confusion of wetlands and cropland.

(3) Zoige plateau is the largest alpine peatland distribution in China with an altitude of $3500 \mathrm{~m}$ and average yearly precipitation of $600-750 \mathrm{~mm}$. Alpine meadow plants, such as Festuca nivina, Kobresia setchuenensis and Elymus nutans, and bog plants such as Carex muliensis and Kobresia tibetica, occurred extensively. 
(4) Mangroves are ecologically and economically important coastal wetlands with high productivity and biodiversity, mainly distributed in the coastal area of South China and Southeast China. More than half of the total mangroves of China are distributed along the coastal areas of Guangdong province. A large amount of mangroves have been exploited for farmland and residential land, especially in the Pearl River estuary.

\subsection{Data sources}

(1) Satellite image data. Four scenes of Landsat TM images located in the above representative regions were obtained from the U.S. Geological Survey (USGS) Earth Resources Observation and Science (EROS) data center (http://glovis.usgs.gov/) and then pre-processed with atmospheric and topographic corrections. Finally, a TC transformation was done and the wetness component was extracted.

Table 2 Landsat TM images list

\begin{tabular}{lcc}
\hline Region & Path/row & Image date \\
\hline Sanjiang Plain & $114 / 027$ & 2010.06 .06 \\
North China Plain & $123 / 032$ & 2010.06 .05 \\
& & \\
Zoige Plateau & $131 / 037$ & 2007.09 .25 \\
& & 2005.07 .18 \\
\hline
\end{tabular}

(2) Topographic data. A 90-m resolution Shuttle Radar Topography Mission (SRTM) DEM was used $^{1}$. The SRTM DEM was used to derive slope, by which the flatten area was determined as the potential wetlands place.

(3) Training and test sample collection. Representative training samples are crucial for supervised classification. The quality as well as the quantity and distribution of samples are also important. There are about 20 - 30 samples in each TM scene, where each sample represents 8 pixels $\times 8$ pixels. Training samples were required to be homogeneous and be distributed in a scene as representative of the major classes presenting in the scene as possible. And the types of the training samples were also required to include all the types of land cover in each scene. Buffers with radius of $120 \mathrm{~m}$ were then produced and assigned values according to their corresponding codes (Table 1). Overlapping buffers with the same

\footnotetext{
${ }^{1} \mathrm{http}: / /$ srtm.csi.cgiar.org/SELECTION/inputCoord.asp 
attribute values were merged and the merged buffers used as training samples.

In each scene, there were about 80 random test samples produced. The class of each test sample was interpreted based on Google Earth and assigned an attribute value according to the wetland classification scheme. Different interpreters have different understanding for the same wetland type, such as marshland. In order to reduce the probability of such inconsistencies, test samples experienced mutual review, group discussion and final check.

\subsection{Workflow of wetland automatic classification based on Landsat TM}

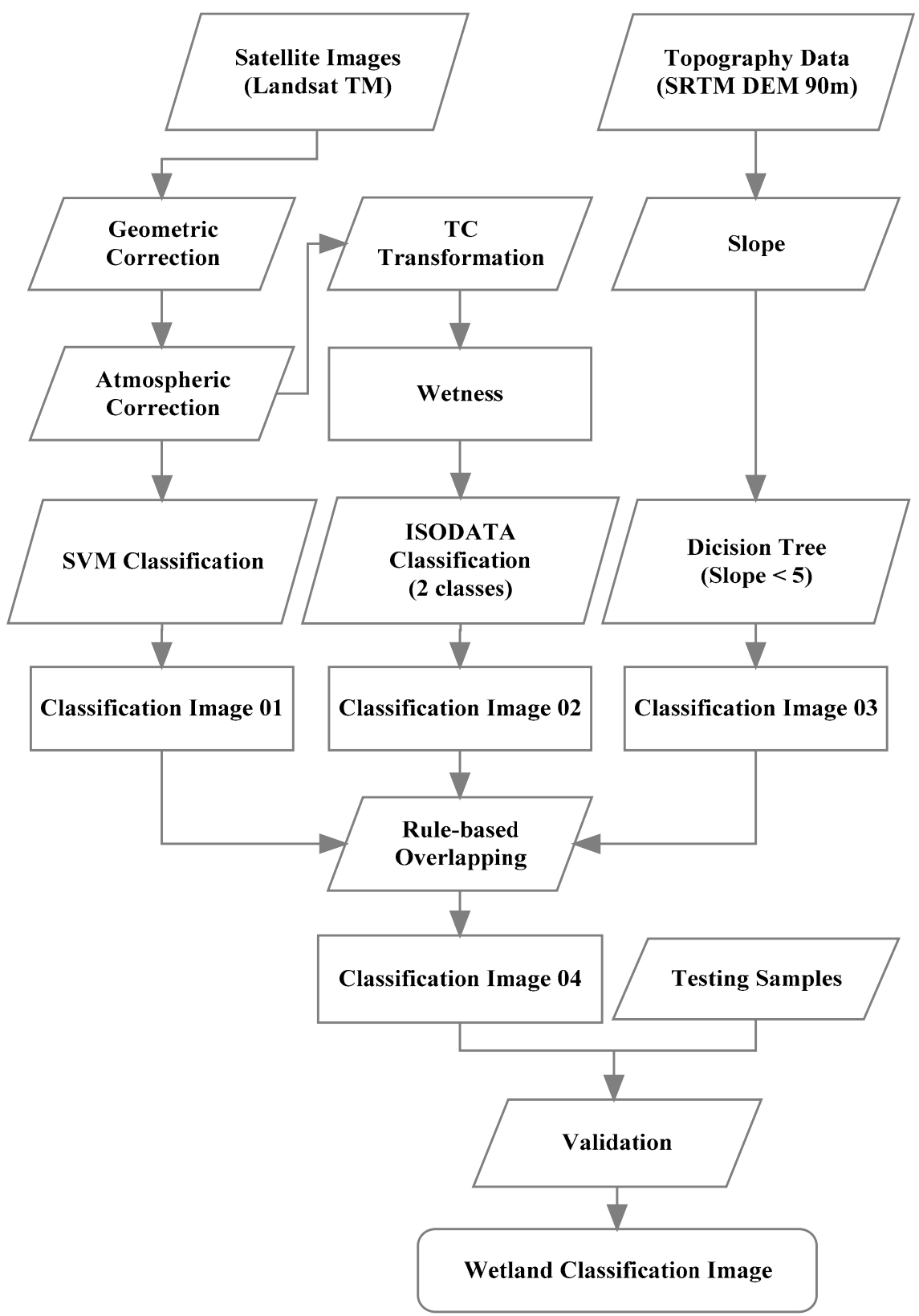

Fig. 2.Flow chart of wetland automatic classification scheme

The overall workflow of wetland automatic classification is shown in Fig. 2. 
The radiometric processing includes atmospheric and topographic corrections, and was conducted automatically. The final product is images of reflectance with the atmospheric and topographic effects substantially reduced. After automatic processing, manual checking was carried out to ensure correction quality. Scenes with a poor quality correction were re-processed with manually selected parameter sets. To evaluate the geometric discrepancy against Google Earth images, we selected 10 ground control points from typical locations to calculate a root mean square error (RMSE). On average, the RMSE was 1.01 pixels, indicating an acceptable level of geometric correction results [32].

Sader et al. [11] found that rule-based methods for forest wetland classification preformed significantly better than unsupervised classification at multiple sites in the northeast United States. We implemented a simple rule-based model (Fig. 2) on pixel-wise basis. Images were classified by using a Support Vector Machine (SVM) and training samples, resulting in a land cover classification map (classification image 01 in Figure 2) according to the land cover categories in Table 1. The image products were also used to make a TC transformation. The wetness component was then extracted and classified by using the ISODATA unsupervised clustering algorithm. Two categories, labeled as the dry and the wet, were produced (classification image 02 in Figure 2). Topographic data (SRTM), corresponding to the image areas, was employed to generate slope map. The slope data was classified into two categories by using threshold of 5 degrees (classification image 03 in Figure 2).

The above three classification maps were then combined according to the rule that pixels with slope less than 5 degree and wet in classification map 02 were considered as wetland and the other pixels were coded to upland. The land cover classification map 01 was used to generate the wetland subcategories. For example, pixels categorized as forest in the classification map 01 were re-coded to forest wetland if they coincided with a wetland. Those pixels coinciding with upland were coded as non-wetland. The final wetland classification map was validated based on test samples.

\section{Results and discussion}

\subsection{Classification results}

Fig. 3 shows the different classification maps produced for the Sanjiang Plain in the rule-based classification model. Besides water and wetlands, the forest category also has high values of wetness (Fig. 3b), indicating that forest, due to high water content of tree, expresses similar characteristic of wetland in the wetness image, which usually lead to confusion between forest and wetland.

Fig. 3d shows the final classification result. Wetland types in this area broadly fall into two categories - water and marshland. Overall accuracy is $86.57 \%$ and the Kappa coefficient is 0.78 . Water has the highest producer accuracy (100\%), followed by the marshland (85\%), non-wetland $(84.62 \%)$ and forest wetland (75\%) (Table 3). The most confusion happens between non-wetland (forest) and forest wetland, which could be caused by the relatively low accuracy of the DEM. Moreover, a small 
portion $(10.53 \%)$ of the non-wetlands which are located near the boundary between marshland and non-wetlands are classified as water. This error was introduced in the SVM classification step, which requires pure pixel samples that are usually difficult to be found in the transitional zone between wetland and non-wetland.

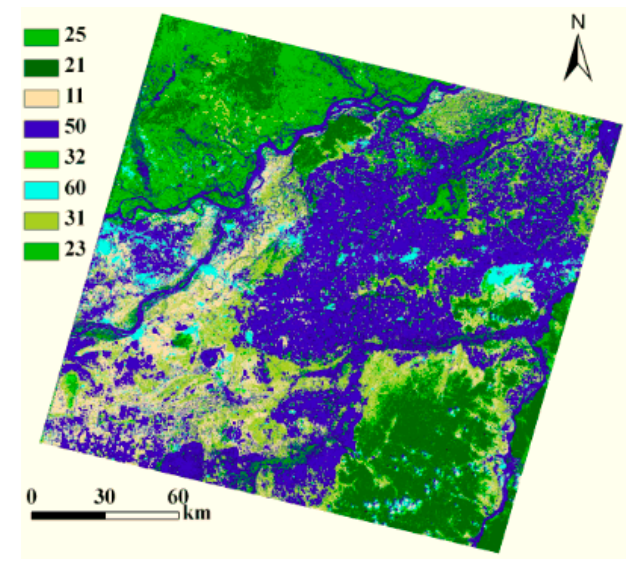

a. SVM classification (11: bare land; 21: forest;

23: grassland; 25: mixture of shrub and grass; 31 : harvested cropland; 32: vegetated cropland; 50: water body; 60: residential land)

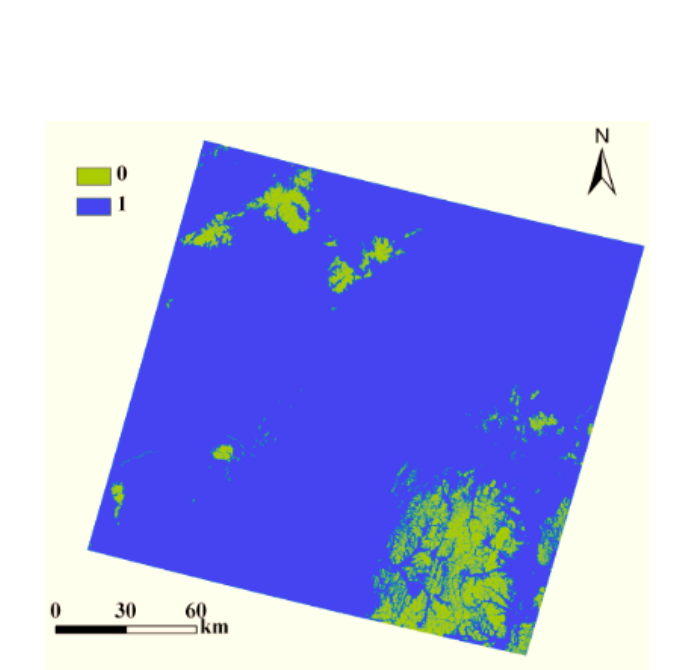

c. classification of slope $\left(1:<5^{\circ} ; 0:>=5^{\circ}\right)$

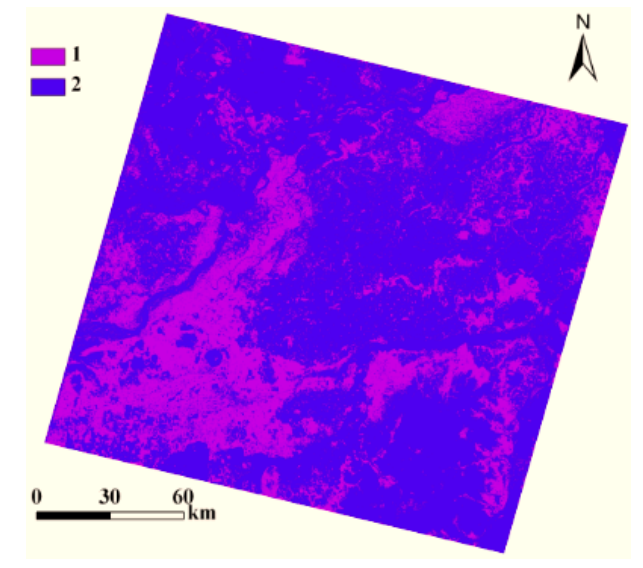

b. ISODATA classification of TC-Wetness (1: the

$$
\text { dry; } 2 \text { : the wet) }
$$

(n)

$$
\text { 西 }
$$

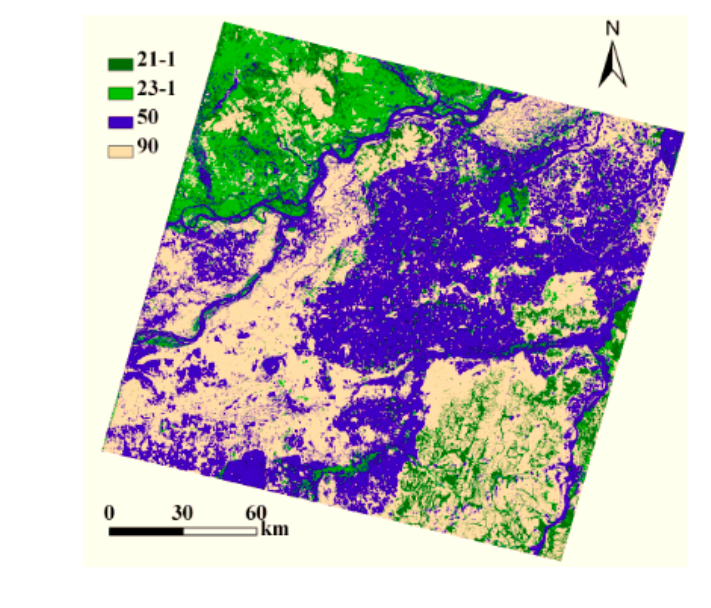

d. (21-1; forest wetland; 23-1: marshland; 50:

$$
\text { water; 90: non-wetland) }
$$

Fig. 3. Classification maps of the Sanjiang Plain

Table 3 Confusion matrix of automatic classification in Sanjiang Plain (\%) 


\begin{tabular}{lccccc}
\hline Festing samples & $\begin{array}{c}\text { Forested } \\
\text { wetlands }\end{array}$ & Marshland & Water & $\begin{array}{c}\text { Non } \\
\text { wetlands }\end{array}$ & Total \\
Forested wetlands & 75 & 0 & 0 & 10.53 & 14.93 \\
Marshland & 0 & 85.71 & 0 & 0 & 8.96 \\
Water & 0 & 0 & 100 & 5.26 & 22.39 \\
Non wetlands & 25 & 14.29 & 0 & 84.62 & 53.73 \\
Total & 100 & 100 & 100 & 100 & 100 \\
\hline
\end{tabular}

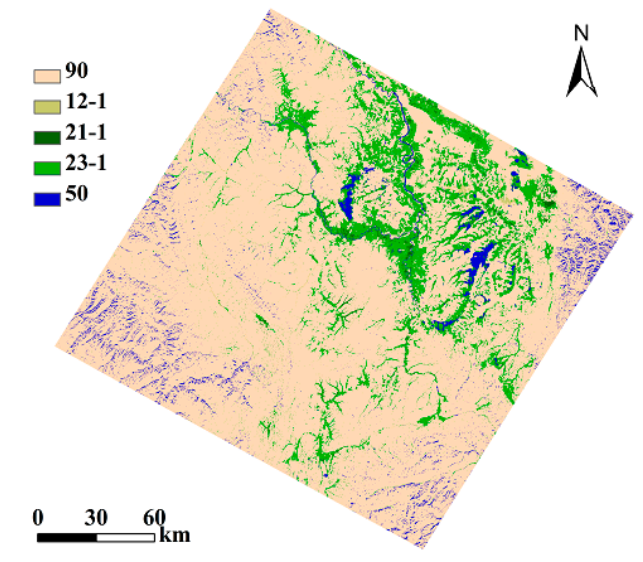

a. Zoige Plateau (12-1: flooded wetland; 21-1: forest wetland; 23-1: marshland; 50: water; 90: non-wetland)

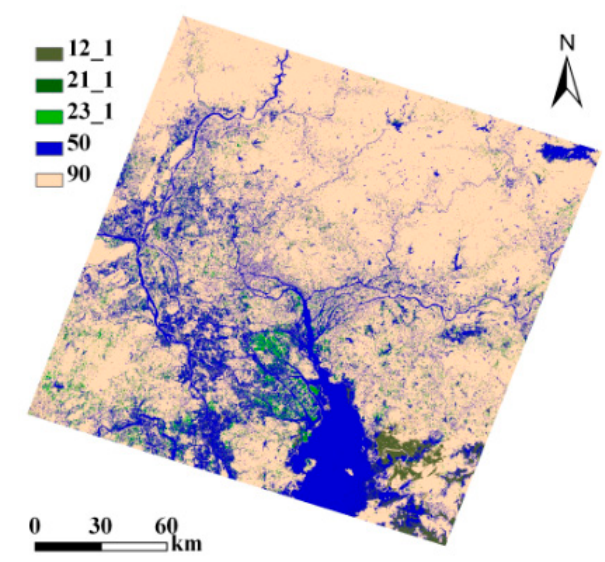

b. Pearl River Estuary（12-1: flooded wetland; 21-1: forest wetland; 23-1: marshland; 50: water; 90: non-wetland ) 


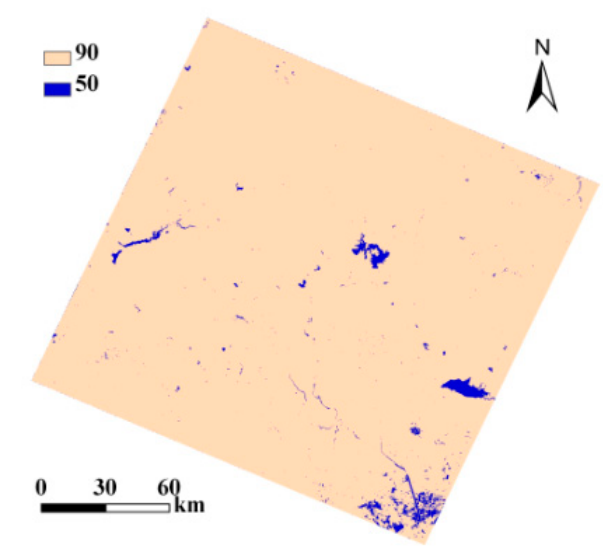

c. North China Plain (90: non-wetland; 50: water)

Fig. 4. Classification maps of the other study areas

Wetland types of Zoige Plateau are comprised of marshland, flooded wetland, forest wetland and water. Its overall accuracy is $84.51 \%$, and the Kappa coefficient is 0.67 . Water, forest wetland and non-wetland have high producer accuracies (Table 4). By contrast, the marshland only has accuracy of $53.85 \%$. We examined the erroneously classified marshland samples and found they were all located at the boundary of marshland and non-wetlands (grasslands). The reason these samples were wrongly classified was that the slope of the samples was more than 5 degrees, the threshold of classification image 03 (Fig. 2). The same phenomenon also contributed to the wrongly classified non-wetland category, a small portion of which was classified as water and marshland. The coarse resolution of the DEM leads to this omission of marshland. 
Table 4 Confusion matrix of wetland classification in Zoige Plateau (\%)

\begin{tabular}{lcccccc} 
& Water & Marshland & $\begin{array}{c}\text { Forested } \\
\text { wetlands }\end{array}$ & $\begin{array}{c}\text { Flooded } \\
\text { wetland }\end{array}$ & $\begin{array}{c}\text { Non } \\
\text { wetlands }\end{array}$ & Total \\
Classification types & & 0 & 0 & 22.22 & 4.12 & 7.75 \\
\hline Water & 83.33 & & & & & \\
Marshland & 16.67 & 53.85 & 0 & 11.11 & 2.06 & 12.68 \\
Forested wetlands & 0 & 0 & 100 & 0 & 0 & 2.82 \\
Flooded wetland & 0 & 0 & 0 & 66.67 & 0 & 4.23 \\
Non wetlands & 0 & 46.15 & 0 & 0 & 93.81 & 72.54 \\
Total & 100 & 100 & 100 & 100 & 100 & 100 \\
\hline
\end{tabular}

Overall accuracy of the image classification for the Pearl River Estuary is $88.30 \%$, and the Kappa coefficient is 0.80 . Among wetland types of this region (Fig 4 b), water and non-wetland have high producer and user accuracy (Table 5). Forest wetland has satisfactory classification accuracy, with only $18 \%$ of test samples erroneously classified as forests, and $9 \%$ of them classified as water. These confusions happened in places where mixed pixels exist between forest and forest wetland. By contrast, marshland (paddy fields with growing crops are also classified as this type) has a low producer accuracy $(62.5 \%)$ and a perfect user accuracy (100\%), in which about $25 \%$ of the paddy fields samples were classified as water, and $12.5 \%$ of marshland samples classified as forested wetlands. These errors were caused in the SVM classification process, which also contributed to the lower producer accuracy of flooded wetland (50\%).

Table 5 Confusion matrix of wetland classification in the Pearl River Estuary (\%)

\begin{tabular}{|c|c|c|c|c|c|c|}
\hline Classification types & Water & $\begin{array}{l}\text { Flooded } \\
\text { wetland }\end{array}$ & Marshland & $\begin{array}{l}\text { Forested } \\
\text { wetlands }\end{array}$ & $\begin{array}{c}\text { Non } \\
\text { wetlands }\end{array}$ & Total \\
\hline Water & 94.64 & 50 & 25 & 9.09 & 0 & 60.64 \\
\hline Flooded wetland & 5.36 & 50 & 0 & 0 & 5.88 & 5.32 \\
\hline
\end{tabular}




\begin{tabular}{lrrrrrr} 
Marshland & 0 & 0 & 62.5 & 0 & 0 & 5.32 \\
Forested wetland & 0 & 0 & 12.5 & 72.73 & 0 & 9.57 \\
Non wetlands & 0 & 0 & 0 & 18.18 & 94.12 & 19.15 \\
Total & 100 & 100 & 100 & 100 & 100 & 100 \\
\hline
\end{tabular}

Only the water category was classified in the image of the North Plain (Fig. 4c) and it has nearly perfect overall accuracy $(96.00 \%)$, with Kappa coefficient 0.92 . Both water and non-wetlands have high producer and user accuracies (Table 6). Being flat topography and extensive agriculture development, less wetland remained in this area, and topographic variable did not contribute to the classification.

Table 6 Confusion matrix of wetland classification in the North China Plain (\%)

\begin{tabular}{lccc}
\hline Classification types & Non wetlands & Total \\
\hline Water & 90 & 0 & 36 \\
Non wetlands & 10 & 100 & 64 \\
Total & 100 & 100 & 100 \\
\hline
\end{tabular}

\subsection{Discussion}

Wetland classification based on solely spectral characteristic is difficult because of spectral confusion with other land cover classes and among different types of wetland. A layer, hybrid or rule-based approach may give better results than more traditional methods, when combined with ancillary data such as soil or elevation data [3]. We showed this method to be effective in classification of various wetland types across China. However, there were still several issues to be addressed.

The wetland was separated from upland based on the combination of ISODATA classification of wetness and threshold of slope data $(<5$ degree). In most cases, this gave a satisfactory classification result, especially the employment of wetness from the TC transformation. However, the coarse resolution of topography data contributed to most errors, especially the marshland omission error. Because the DEM used here has a spatial resolution of $90 \mathrm{~m}$, which does not match the resolution of the TM satellite images, minor topographic changes were often neglected or could not be easily 
discriminated. For example, in Zoige Plateau, many marshland samples were misclassified as grasslands as a result of the coarse resolution of the slope data generated from the 90m DEM.

The wetland types were classified by using an SVM trained on human interpreted classes. The quality of training samples is key for the SVM classification of land cover. Wetlands were commonly considered as transitional zone between terrestrial and aquatic ecosystems and have mixed spectral characteristics of water and vegetation. It is very difficult to choose pure pixels for training samples, which are important for SVM classification. As a result of the test samples being generated by random sampling, there were many test samples located along the boundaries of two different wetland types. Different interpreters can have different understanding of the same wetland type such as shallow water and water-logged sparse marshland. Since the training samples and the test samples were interpreted by different people, different understanding of wetland types led to most wetland commissions in our study, indicating an outstanding issue in wetland classification in the future.

\section{Conclusion}

To conserve and manage wetland resources, it is important to inventory and monitor wetlands and their adjacent uplands. Though satellite remote sensing has been shown to be an effective method for monitoring wetlands, there is little literature about automatic mapping of wetlands for large geographic areas. By coupling supervised classification (SVM and decision tree) and unsupervised classification (ISODATA), we developed an operational rule-based classification approach.

To meet the requirements of wetland automatic classification, a revised wetland classification system was suggested, in which seven wetland types were considered and other wetland characteristics such as wetness, topographic characteristics, and hydrological characteristics were considered.

Four representative wetland distributed regions across China were chosen to examine the feasibility of the approach we suggested. Classification results showed that the overall accuracies (above 80\%) were satisfactory in those four regions. This method demonstrates a potential quick and accurate strategy for mapping China wetland across various geographic regions and wetland categories.

The selection of variables, such as wetness of TC transformation and slope derived from topographic data, contribute greatly to the increased overall accuracy of wetlands classification. However, the limitation of coarse resolution of topography data $(90 \mathrm{~m})$ gave rise to the most omission errors. Misunderstanding by human interpreters of wetland cover types also contributed to classification error.

Acknowledgement: This research was jointly supported by National Science \& Technology Support Plan Project (2012BAJ24B01), National Natural Science Foundation of China (41271423) and National High Technology Grant from China (2009AA122003). 


\section{References}

[1] C. M. Finlayson and A. van der Valk, Classification and inventory of the world's wetlands: Kluwer Academic Pub, 1995.

[2] L. S. McAllister, et al., "A synoptic assessment for prioritizing wetland restoration efforts to optimize flood attenuation," Wetlands, vol. 20, no. 1, pp. 70-83, 2000.

[3] S. L. Ozesmi and M. E. Bauer, "Satellite remote sensing of wetlands," Wetlands Ecology and Management, vol. 10, no. 5, pp. 381-402, 2002.

[4] R. A. Fournier, et al., "Towards a strategy to implement the Canadian Wetland Inventory using satellite remote sensing," Canadian Journal of Remote Sensing, vol. 33, no. 1, pp. S1-S16, 2007.

[5] F. M. Henderson and A. J. Lewis, "Radar detection of wetland ecosystems: a review," International Journal of Remote Sensing, vol. 29, no. 20, pp. 5809-5835, 2008.

[6] H. MacKay, et al., "The role of Earth Observation (EO) technologies in supporting implementation of the Ramsar Convention on Wetlands," Journal of Environmental Management, vol. 90, no. 7, pp. 2234-2242, 2009.

[7] M. Green, E. Friedler, and I. Safrai, "Enhancing nitrification in vertical flow constructed wetland utilizing a passive air pump," Water Research, vol. 32, no. 12, pp. 3513-3520, 1998.

[8] D. Alsdorf, et al., "Measuring global oceans and terrestrial freshwater from space," Eos, Transactions American Geophysical Union, vol. 88, no. 24, pp. 253, 2007.

[9] T. Nakaegawa, "Comparison of water-related land cover types in six 1-km global land cover datasets," Journal of Hydrometeorology, vol. 13, no. 2, pp. 649-664, 2012.

[10] K. O. Pope, J. M. Rey-Benayas, and J. F. Paris, "Radar remote sensing of forest and wetland ecosystems in the Central American tropics," Remote Sensing of Environment, vol. 48, no. 2, pp. 205-219, 1994.

[11] S. A. Sader, D. Ahl, and W.-S. Liou, "Accuracy of Landsat-TM and GIS rule-based methods for forest wetland classification in Maine," Remote Sensing of Environment, vol. 53, no. 3, pp. 133-144, 1995.

[12] E. W. Ramsey III and S. C. Laine, "Comparison of Landsat Thematic Mapper and high resolution photography to identify change in complex coastal wetlands," Journal of Coastal Research, vol. 13, no. 2, pp. 281-292, 1997.

[13] R. S. Lunetta and M. E. Balogh, "Application of multi-temporal Landsat 5 TM imagery for wetland identification," Photogrammetric Engineering and Remote Sensing, vol. 65, no. 11, pp. 1303-1310, 1999.

[14] K. R. Harvey and G. J. E. Hill, "Vegetation mapping of a tropical freshwater swamp in the Northern Territory, Australia: a comparison of aerial photography, Landsat TM and SPOT satellite imagery," International Journal of Remote Sensing, vol. 22, no. 15, pp. 2911-2925, 
2001.

[15] P. A. Townsend and S. J. Walsh, "Remote sensing of forested wetlands: application of multitemporal and multispectral satellite imagery to determine plant community composition and structure in southeastern USA," Plant Ecology, vol. 157, no. 2, pp. 129-149, 2001.

[16] R. L. Phillips, O. Beeri, and E. S. DeKeyser, "Remote wetland assessment for Missouri Coteau prairie glacial basins," Wetlands, vol. 25, no. 2, pp. 335-349, 2005.

[17] C. Baker, et al., "Mapping wetlands and riparian areas using Landsat ETM+ imagery and decision-tree-based models," Wetlands, vol. 26, no. 2, pp. 465-474, 2006.

[18] C. Wright and A. Gallant, "Improved wetland remote sensing in Yellowstone National Park using classification trees to combine TM imagery and ancillary environmental data," Remote Sensing of Environment, vol. 107, no. 4, pp. 582-605, 2007.

[19] Z. G. Niu, et al., "Mapping wetland changes in China between 1978 and 2008," Chinese Science Bulletin, vol. 57, no. 22, pp. 2813-2823, 2012.

[20] Z. G. Niu, H. Y. Zhang, and P. Gong, "More protection for China's wetlands," Nature, vol. 471, pp. 305, 2011.

[21] Z. G. Niu, et al., "Geographical characteristics of China's wetlands derived from remotely sensed data," Science in China (Series D: Earth Sciences), vol. 52, no. 6, pp. 723-738, 2009.

[22] P. Gong, et al., "China's wetland change (1990-2000) determined by remote sensing," Science in China (Earth Sciences), vol. 53, no. 7, pp. 1036-1042, 2010.

[23] ACOE, Corps of engineers wetland delineation manual: Technical report Y-87-1. US Army Corps of Engineer Waterways Experiment Station, Vicksburg, MS, USA, 1987.

[24] T. Landmann, et al., "MODIS-based change vector analysis for assessing wetland dynamics in Southern Africa," Remote Sensing Letters, vol. 4, no. 2, pp. 104-113, 2012.

[25] R. J. Kauth and G. Thomas, The tasselled cap--a graphic description of the spectral-temporal development of agricultural crops as seen by Landsat, in LARS Symposia. 1976.

[26] S. P. Healey, et al., "Comparison of Tasseled Cap-based Landsat data structures for use in forest disturbance detection," Remote Sensing of Environment, vol. 97, no. 3, pp. 301-310, 2005.

[27] P. Merot, et al., "Testing a climato-topographic index for predicting wetlands distribution along an European climate gradient," Ecological Modelling, vol. 163, no. 1, pp. 51-71, 2003.

[28] L. McKergow, J. Gallant, and T. Dowling, "Modelling wetland extent using terrain indices, Lake Taupo, NZ," pp. 1335-1341, 2007.

[29] T. Grabs, et al., "Modeling spatial patterns of saturated areas: A comparison of the topographic wetness index and a dynamic distributed model," Journal of Hydrology, vol. 373, no. 1, pp. 15-23, 2009.

[30] M. T. Coe, "A linked global model of terrestrial hydrologic processes: Simulation of modern rivers, lakes, and wetlands," Journal of geophysical research, vol. 103, no. D8, pp. 8885-8899, 1998. 
[31] Ramsar Convention Secretariat, The Ramsar Convention Manual: a guide to the Convention on Wetlands (Ramsar, Iran, 1971), 4th ed. Ramsar Convention Secretariat, Gland, Switzerland, 2006.

[32] P. Gong, et al., "Finer resolution observation and monitoring of global land cover: first mapping results with Landsat TM and ETM+ data," International Journal of Remote Sensing, vol. 34, no. 7, pp. 2607-2654, 2012. 